\title{
O “LUGAR" DO TRABALHO NA TOTALIDADE SOCIAL: DA CENTRALIDADE ONTOLÓGICA À CENTRALIDADE "PERIFÉRICA" DA FORÇA DE TRABALHO
}

\author{
André Luis Amorim de Oliveira ${ }^{1}$
}

\begin{abstract}
RESUMO: No artigo em tela recorremos à algumas das importantes indicações feitas por Fortes (2016) que, ao analisar o complexo do trabalho em Lukács, particularmente, na obra madura deste autor, isto é: Por um Ontologia do Ser Social(2012, 2013), elenca uma série de questões relevantes que contribuem para a compreensão do "lugar" ontológico do trabalho na totalidade social, o que, por conseguinte, diz respeito ao debate da ontologia do espaço na Geografia. Aliado às contribuições da Geografia, bem como as ponderações de Fortes (2016) com base em Lukács $(2012$, 2013), procuramos, portanto, retomar o problema da centralidade do trabalho enquanto fundamento do ser social (espacial). Ao mesmo tempo, ao final, buscamos destacar, breve e sinteticamente, o problema da superexploração da força de trabalho enquanto fundamento do capitalismo dependente.
\end{abstract}

PALAVRAS-CHAVE: Geografia; marxismo; filosofia; trabalho; capitalismo dependente

\section{THE "PLACE” OF WORK IN SOCIAL TOTALITY: FROM ONTOLOGICAL CENTRALITY TO THE “PERIPHERAL” CENTRALITY OF WORKFORCE}

ABSTRACT: In this article, we resort to some of the important indications made by Fortes (2016) who, when analyzing the complex of work in Lukács, particularly in this author's mature work, that is: For an Ontology of Social Being $(2012,2013)$, lists a series of relevant questions that contribute to the understanding of the ontological "place" of work in the social totality, which, therefore, concerns the debate on the ontology of space in Geography. Allied to the contributions of Geography, as well as the considerations of Fortes (2016) based on Lukács $(2012,2013)$, we seek, therefore, to return to the problem of the centrality of work as the foundation of the social (spatial) being. At the same time, at the end, we seek to highlight, briefly and synthetically, the problem of the overexploitation of the labor force as the foundation of dependent capitalism.

KEYWORDS: Geography; marxism; philosophy; work; dependent capitalism.

\footnotetext{
${ }^{1}$ Doutor em Geografia pela Faculdade de Filosofia, Letras e Ciências Humanas da Universidade de São Paulo. E-mail: andre13tl@gmail.com
} 


\section{EL “LUGAR” DE TRABAJO EN LA TOTALIDAD SOCIAL: DE LA CENTRALIDAD ONTOLÓGICA A LA CENTRALIDAD “PERIFÉRICA” DE LA FUERZA LABORAL}

RESUMEN: en este artículo recurrimos a algunas de las importantes indicaciones de Fortes (2016) quien, al analizar el complejo de trabajo en Lukács, particularmente en la obra madura de este autor, es decir: Por una ontología del ser social $(2012,2013)$, enumera una serie de cuestiones relevantes que contribuyen a la comprensión del "lugar" ontológico del trabajo en la totalidad social, que, por tanto, concierne al debate sobre la ontología del espacio en Geografía. Aliados a los aportes de la Geografía, así como a las consideraciones de Fortes (2016) con base en Lukács (2012, 2013), buscamos, por tanto, volver al problema de la centralidad del trabajo como fundamento de lo social (espacial). ser. Al mismo tiempo, al final, buscamos resaltar, de manera breve y sintética, el problema de la sobreexplotación de la fuerza de trabajo como fundamento del capitalismo dependiente.

PALABRAS-CLAVE: Geografía, marxismo; filosofía, trabajo, capitalismo dependiente.

INTRODUÇÃO

O "[...] trabalho não é uma das muitas formas fenomênicas da teleologia em geral, mas o único lugar onde se pode demonstrar ontologicamente a presença de um verdadeiro pôr teleológico como momento efetivo da realidade material" (LUKÁCS, 2012, p. 13-14).

Reanimar o debate sobre a importância da categoria trabalho na Geografia brasileira e, particularmente na Geografia crítica, é sempre importante, visto que esta categoria continua sendo atual e vigente como aspecto para a compreensão espaço geográfico e suas transformações. No entanto, nem sempre o trata tem sido pormenorizado em sua dimensão dentro do complexo da totalidade social, notadamente quando se parte de Marx (2013), Lukács $(2012,2013)$ e mais recentemente de Mészáros $(2002,2006)$ para reafirmar a importância do trabalho como mediação fundamente e fundamental do espaço geográfico.

No texto que se segue o objetivo é tentar contribuir para este debate sobre o trabalho, atentando, a partir das indicações de Lukács (2012, 2013), Fortes (2016) e demais autores dentro e fora da Geografia sobre o tema da chamada 
centralidade do trabalho tentando. Com isso, procuramos reforçar a aproximação entre a Geografia crítica e o debate filosófico (e ontológico) marxista. Esta singela tentativa de contribuição é feita em tom polêmico, demarcando um posicionamento teórico (e político) marxista em contraposição à incorporação, reprodução e até banalização de termos como a centralidade do trabalho atribuída com frequência a Marx $(2004,2013)$ e Lukács $(2021,2013)$ sem que se de maiores explicações.

Cabe destacar que na proposta ora apresentada, a investigação justifica-se pela necessidade de análise da validade e capacidade de explicação (potencialidades e limites) sempre (re)postas pela dinâmica da práxis social, o que implica a contínua retomada e análise crítica de pressupostos e categorias, nesse caso, marxistas, que se referem à temática da ontologia na geografia (SILVA, 1978, MORAES, 1982, BITETI, 2007, MARTINS, 2007, REIS, 2009, PEDROSA, 2012, OLIVEIRA JR. 2015) aqui retomada na sua versão "lukasciana enquanto uma perspectiva específica" (OLIVEIRA, 2015, p. 10).

Portanto, seguindo as trilhas de autores que, além do próprio Lukács, buscam um tratamento e procedimento adequado da categoria trabalho, é que se pretende validar o papel qualitativo e fundante do trabalho dentro do enorme escopo da ontologia lukasciana, até porque, há no Brasil um expressivo conjunto de pesquisas e material que trata das obras deste autor, notadamente de sua Ontologia, o que sugere a "pertinência de debates contemporâneos no âmbito das reflexões desenvolvidas por Lukács e a atualidade da proposta empreendida pelo autor" (OLIVEIRA, 2015, p. 10).

Ademais, o debate acerca da relevância de argumentos ontológicos calcados na especificidade da categoria trabalho na ontologia marxista, direcionase ainda, concomitantemente, à reflexão e crítica epistemológica, somando-se à estas, o que aponta, do mesmo modo, "para apropriações de elementos do conhecimento filosófico e as potencialidades de integração para reforçar 
questões atinentes aos aspectos gnosiológicos da ciência no apropriar-se da realidade" (OLIVEIRA, 2015, p. 11).

É preciso lembrar ainda, como subsídio justificador, que a atividade produtiva como fundamento do ser social (espacial), ou seja, reconhecida tal como Lukács $(2012,2013)$ a situa dentro do "complexo de complexos" da totalidade social traz para o primeiro plano a dimensão humana do trabalho identificada por Marx (2004) já nos Manuscritos Econômico-filosóficos de 1844, de modo que o trabalho desse ponto de vista, isto é, como mediação de primeira ordem (MÉSZÁROS, 2002) entre o ser social e natureza e, portanto, produtor de valor de uso e responsável pela reprodução de qualquer forma de sociedade. Dessa perceptiva, o trabalho é um aspecto fundamental dentro de quadro de possibilidades rumo à uma transformação societal emancipada e livre.

Cabe ainda destacar certa concordância com Santos e Souza (2017) sobre a retomada do tema, nesse caso o da centralidade do trabalho, já que a análise aqui proposta guia-se pelos caminhos trilhados pela geografia da práxis movida pela necessidade de compreensão/transformação/superação dos problemas identificados, daí a indicação política anterior, ou seja, que o debate sobre o trabalho pressupõe asseverar a dimensão crítica iniciada no contexto do pensamento geográfico brasileiro nas décadas de 1980 e 1990.

Até porque, se há uma tendência de "refluxo" dessa corrente, conforme expressão utilizada por Carlos (2007) ${ }^{2}$, em certo sentido, tal recrudescimento envolve os (des)caminhos da ciência geográfica diante das transformações capitalistas, ou seja, à dinâmica (limites e potencialidades) da crítica diante no novo espirito do tempo (Zeitgeist) de um capitalismo que para Mészáros (2002) vivencia sua crise estrutural, momento em que se tem a irrupção da dita "pós-

\footnotetext{
${ }^{2}$ Segundo a autora, as transformações na Geografia revelariam que o pensamento crítico e radical que avançou muito no Brasil nas décadas de 1970 e 1980 entrou "em refluxo". A Geografia, continua a autora, estaria "inundada pelo pensamento neoliberal. Assim, a atividade de pesquisa se vê submetida às exigências do mercado, recolocando a questão do papel do geógrafo na compreensão da sociedade atual" (CARLOS, 2007, s/p).
} 
modernidade" com forte influência cultural, teórica e política, torna-se assim, arriscamos dizer, hegemônica, em consonância (ideológica) com o espírito deste tempo de crise (NETTO, 2010, p. 258).

Contudo e por fim, uma retomada crítica sobre o trabalho posta nos termos de um debate que foi mais intenso nos anos de 1980 e 1990, não pode, a nosso ver, deixar de lado a especificidade estrutural e sistêmica da força de trabalho em uma economia dependente como a brasileira, daí que cabe ao menos indicar, em sentido aproximativo, o problema da superexploração da força de trabalho identificado e destacado primeiramente por Ruy Mauro Marini e pela Teoria Marxista da Dependência que este ajudou a formular a partir da década de 1960.

Se o debate sobre o trabalho dentro da Geografia era acalorado nos anos de 1980 e 1990, a TMD e, particularmente, o tratamento dado ao trabalho por Marini passava ao largo das discussões na Geografia, a partir dos anos 2000, com a retomada da TMD e o destaque de sua importância para a compreensão das transformações no espaço brasileiro, entendemos que essa incorporação à Geografia e, particularmente, ao debate sobre o trabalho, é fundamental visto "o caráter central da superexploração da força de trabalho como característica específica das economias dependentes (CARCANHOLO, 2013, p. 191), o que remete diretamente ao modus operandido capitalismo dependente no território brasileiro e, por conseguinte, a relevância da TMD para a compreensão contemporânea da força de trabalho, notadamente no que tange à dimensão da luta política.

No primeiro item do texto ora apresentado retomamos de forma sintética a questão do trabalho na Geografia e a contribuição de alguns dos principais autores que trataram do tema de um ponto de vista ontológico. Ao mesmo tempo, alertamos para nossa posição contraria à negação da centralidade do trabalho enquanto fundamento do ser social e espacial. 
No segundo e terceiros itens procuramos retomar o autor marxista que, a nosso ver, melhor tratou do problema do trabalho de um ponto de vista ontológico, que foi Lukács em sua obra Por uma Ontologia do Ser Social. Nesse caso recorremos às indicações de Fortes (2016), autor que, numa mesma chave, tratou rigorosamente este complexo em Lukács, criticou a ideia de "centralidade" de trabalho que não como fundamento e parte constitutiva de toda uma "rede" complexa de categorias ligadas à reprodução e, ao mesmo tempo, apontou para o problema da vulgarização que a noção de centralidade assumiu e assume em certas abordagens.

Ao final, nas considerações, buscamos destacar, ao invés de fechar o debate, deixa-lo aberto, sintetizando de modo breve o problema da superexploração da força de trabalho enquanto fundamento do capitalismo dependente. Nesse caso, contudo, redirecionamos a discussão para o aspecto político, ou seja, como mediação que, em sua autonomia relativa, está ligada à totalidade do capitalismo dependente (MARINI, 2005, BAMBIRRA, 2019) e, portanto, deve ser considerada. Com isso, intentamos ainda, de forma inicial e tateando sobre o tema, sinalizar para a importância da Geografia se voltar também para a "centralidade política" da classe trabalhadora brasileira à luz da Teoria Marxista da Dependência tendo em vista as leis tendências específicas que envolvendo a condição "periférica" do capitalismo dependente.

\section{ESPAÇO, ONTOLOGIA E TRABALHO: CONTRIBUIÇÕES DA GEOGRAFIA}

Parece ter se tornado quase senso comum em alguns redutos acadêmicos o uso dos termos "centralidade do trabalho", "centralidade ontológica do trabalho" ou "ontologia do trabalho", por parte de um conjunto de pensadores. Tomados de forma apressada com referência seja a Marx (2004, 2013) seja a Lukács (2012, 2013), por vezes o procedimento que incorpora tais termos além de identificar (a priori) a presença inquestionável destes nas obras de ambos, salta-se 
rapidamente para uma equalização do trato do trabalho feito por Marx ao que seguiu na proposto de Lukács.

As implicações e limites dessas posições resultam, por vezes, em imputações (e amputações) simplistas e simplificadoras sem que nem sempre um tratamento (imanente) seja conduzido de modo a trazer para o primeiro plano o real significado da categoria trabalho para estes autores e, por conseguinte, como complexo mediador fundamente e fundamental do ser social e do espaço geográfico.

Uma retomada crítica nesse sentido não é, contudo, mero preciosismo de uma em uma disputa por termos, ainda que estes não sejam "inocentes", ao contrário, visa contribuir singelamente para o tratamento de um problema complexo e polemico que que se refere à ontologia do ser social e o espaço geográfico, ou da ontologia do espaço (SILVA, 1982, MOREIRA, 2002, 2004, 2011, MARTINS, 2007, 2014, REIS, 2009, 2012, OLIVEIRA Jr., 2015), tema de suma importância que diz respeito à "construção de um trajeto entre filosofia e geografia por meio da ontologia" (Idem, p. 1).

Se um esforço reflexivo sobre a categoria trabalho ou sua centralidade demanda uma investigação à luz de sua relevância e constituição como atividade fundante do ser social, essa compreensão do trabalho na gênese (ou como fundamento) do ser social não pode, no entanto, ser considerada através de meras afirmações auto evidentes, incorporadas a partir de terceiros e reproduzidas (e até banalizadas) por vezes como sendo próprias de Marx (2004, 2013) ou de Lukács (2012, 2013), sem uma verificação correspondente que de subsídios a tais afirmações categóricas. Antes de avançarmos, porém, faremos três apontamentos:

1) Como se sabe, em suas mais variadas matizes e nos mais diversos campos da ciência, as negações ou o descarte do trabalho, como bem lembrou Fortes (2016), costumam se apoiar na estratégica e engenhosamente crítica ao 
trabalho através da construção de espantalhos teóricos, imputando, por exemplo, às elaborações marxianas e lukascianas a elevação do trabalho ao status de "mais alta categoria, como a mais estimada de todas as atividades humanas", como escreveu Arendt (1981, p. 113) a respeito de Marx. Assim, é atribuído com frequência à teoria de Marx ou de Lukács, que o trabalho seria a "mais alta categoria".

Citando novamente a Arendt: "o título da grande obra de Marx é inadequado: deveria ter sido System der Arbeit' (Idem, p. 113). Deste modo, a dupla dimensão do trabalho (ontológica e histórica) já bastante conhecida de Marx e adensada por Lukács, assim como a relação dialética entre capital e trabalho como momentos da processualidade histórica envolvendo aluta de classes, sofre com um profundo reducionismo, ao mesmo tempo em que ambos autores são criticados por "darem muita atenção ao trabalho".

O procedimento de desconstrução da centralidade do trabalho posto nestes termos fica ainda mais fácil quando se volta para as transformações do dito capitalismo "avançado",4 ou melhor, central (e, não por acaso, frequentemente feitas por autores que vivenciam as contradições de lá). Isso porque, devido à uma série de fatores, principalmente tecnológico, esta nova etapa do capitalismo engendraria o suposto "fim do trabalho", o "fim do valor" e do "fim do proletariado" (GORZ, 1987, OFFE, 1985, HABERMAS, 1989, KURZ, 1992, AZNAR, 1995, CASTELLS, 1999). Na época caracterizada por distintos nomes: "Sociedade de consumo", "Sociedade de serviços", "Sociedade informacional", “Sociedade em rede”, "pós-industrial”, “pós-trabalho”, “pós-classista”, etc.

\footnotetext{
${ }^{3}$ Foi assim que Arendt (1981, p. 113), por exemplo, descreveu equivocadamente o problema do trabalho em Marx: "A súbita espetacular promoção do labor, da mais humilde e desprezível posição à mais alta categoria [...] atingiu o clímax no [pensamento] de Marx, no qual o labor passou a ser a origem de toda a produtividade e a expressão da própria humanidade do homem".

4 Gorz (1987), um dos principais autores a proporem o "fim do trabalho" e o "fim do proletariado", formulou o novo e curioso conceito de "não-classe de proletários pós-industriais" para tentar explicar as mudanças no "mundo do trabalho".
} 
Gorz (2003), por exemplo, escreveu sobre a "a diminuição progressiva do trabalho", de modo que na sociedade "predominem as atividades autônomas; o tempo livre prevalecerá sobre o tempo coagido, o lazer sobre o trabalho" (GORZ, 2003, p. 177). E Aznar (1995), cujo título do livro mais conhecido é: "Trabalhar menos para trabalharem todos", também tentaram emplacar a tese do "fim do trabalho".

As concepções sobre o fim do trabalho tiveram mais força no início dos anos de 1980 e, particularmente, em 1990 no Brasil, mas, apesar da tentativas, depois que as transformações tecnológicas tão conclamadas e as contínuas crises do capital impuseram não o fim do trabalho, mas a ampliação do desemprego estrutural e dos empregos precários e, no caso do Brasil, a intensificação da superexploração da força de trabalho - sem contar outros tantos milhões de trabalhadores em regiões como a China e a Índia, só para ficarmos em alguns exemplos -, tais teses, que já não tinham uma base de sustentação tão firme na realidade, parecem ter arrefecido, ainda que sinalizassem para problemas que de fato estavam e estão ocorrendo no "mundo do trabalho". Ademais, contraposições críticas às teses do "fim do trabalho" já foram feitas com maior ou menor rigor por autores como Antunes (1995, 1999), Lessa (2012), Prieb (2005), dentre outros.

Aliás, estas transformações, como não poderia deixar de ser, impactaram a ciência geográfica e, segundo Francesconi (2006), impulsionaram, junto com a chamada Geografia Crítica, o desenvolvimento de uma "Geografia do Trabalho", termo que foi proposto por Pierre George, mas não foi levado adiante por uma série de limitações teóricas e epistemológicas (MENEZES, 2020, p. 167), mas que mais tarde seria retomado por Moreira (2001) e Thomaz Jr. (2004). O primeiro utilizando o termo "com letra minúscula ["geografia do trabalho"], não como uma nova corrente da Geografia" (MOREIRA, 2001, p. 42), ou seja, "aquela voltada para o conjunto de temáticas que envolve as relações de produção e as condições do 
trabalhador no processo de produção do espaço"; e o segundo, propondo uma "Geografia do trabalho" como sendo um novo campo de investigação geográfico “da estrutura de poder e do controle social exercido pelo capital sobre a sociedade e, em particular sobre o trabalho (THOMAZ Jr. 2004, p. 10).

2) Não coadunamos com a noção pós-moderna frágil e sem base concreta de "descentramento do sujeito", a qual, apesar dessas características, acaba por se desdobrar, como bem apontou Rodrigues (2006, p. 17), em um sujeito “incapaz de compreender coerentemente o mundo e de intervir nele de forma consciente", problema que frequentemente desemboca ainda em uma visão na qual as "lutas descentradas, anárquicas e transgressivas que, empreendidas por múltiplos sujeitos, não têm por meta a superação da ordem vigente, mas o choque com o poder-saber" (RODRIGUES, 2006, p. ), o que invariavelmente remete à uma certa leitura calcada Nietzsche, sinaliza ainda essa autora.

Nesse tipo de idealização (ou idealismo subjetivista, diria Lukács), o papel do trabalho (e dos trabalhadores) aparece geralmente como só mais uma manifestação (imediata/formal) da economia diante da pluralidade do mundo (do trabalho). A Geografia não escapou a isso, pois , ao menos até meados dos anos de 1970, o trabalho era tratado, conforme apontou Cavalcanti (2020, p. 86), como mais um "fator de produção" "em estudos que enumeravam as atividades, apontavam os custos de produção e a distribuição dos empregos", naquilo que ficou conhecido como "geografia dos empregos" representada por nomes como o de Vidal de La Blache ou em Pierre George (1969, p. 93) que entende o trabalho como fator de "produção e modo de existência, envolvendo a ação dos grupos humanos em quadros temporais definidos com base na forma do meio em que vivem e desenvolvem sua atividade". Para Moreira (2008, p. 177), é só em Elise Reclus, Brunhes e George que o trabalho ganha um status conceitual de mais clara evidência teórica, ainda que cada um a seu modo e dentro de certos limites teóricos e políticos. 
Em tais condições históricas do desenvolvimento da ciência geográfica, a dimensão política (e de classes) do trabalho não aparecia, ficando subsumida nos debates epistêmicos que se detinham sobre a categoria trabalho. Mais grave ainda, era uma concepção de segundo a qual o trabalho seria um atributo natural e anistórico do ser social, hipotecada no discurso naturalizante do capitalismo da Economia política até a crítica demolidora de Marx.

Se, portanto, a renovação da geografia nos de 1970 sob a influência do marxismo (ainda que fosse um marxismo de forte tom leninista) trouxe transformações em relação ao problema do trabalho (FRANCESCONI, 2006), ainda assim, a categoria, que passou a ser considerado sob outra ótica, esteve envolta em problemas, visto que, conforme Moreira (2004), nessa renovação, a geografia radical ou crítica ao centrar o "diálogo no entendimento restrito da categoria da natureza, do trabalho e da riqueza enquanto formas de expressão das categorias do valor econômico numa economia de mercado” (MOREIRA, 2004, p. 27) “[...] deu como produto uma economia política do espaço basicamente" (Ibidem).

Ademais, a dimensão ontológica e dialética do trabalho era ora ignorada, ora tangenciada, o que começou a mudar somente a partir dos anos de 1980, com Moreira (1982) e outros. Ainda assim, esse acento ontológico era incipiente e, por vezes, combinado por um certo politicismo, caindo, a nosso ver, não raro, na ênfase demasiada da "centralidade epistêmica" do trabalho, o que era compressivo, tendo em vista que as influências do positivismo ainda eram marcantes no período. Novamente o quadro se altera a partir da década de 1990 e 2000 quando autores como Lefébvre (2006), Smith (1988), Harvey (1980, 1992, 2000), Lukács (2012, 2013) e Mészáros (2002, 2006), passam a exercer certa influência em autores da Geografia brasileira que tratavam o tema do trabalho mais detidamente como Moreira (1985, 2001), Thomaz Jr. $(2002,2004)$.

Recuperando este complexo mediador entre ser social e natureza, ou seja, a mediação sociometabólica entre ser social e natureza como condição para a 
reprodução do espaço (e do próprio ser), cuja complexificação liga-se aos processos (teleológicos) das formas de práxis social, cabe enfatizar que, distinta de uma posição que visa "contemplar" a condição existencial do homem-nomundo a partir de uma perceptiva existencialista e fenomenológica ou de uma "geograficidade" amparada em "experiências", no "modo de ser" ou na "prática espacial", nosso "guia" é o próprio ser social determinado historicamente ("complexo de complexos") e suas múltiplas formas de práxis tal qual indicado por Marx (2004) e Lukács (2012, 2013).

Acentuar esse caráter mediador, exige, portanto, num primeiro movimento, retomar a impostação ontológica que indique o "lugar" do trabalho na totalidade social ou como "complexo de complexos" determinante/determinado dentro da dinâmica a produção do espaço geográfico, daí que as leituras geográficas que propõem uma centralidade do trabalho que não apontam nesse sentido (do "lugar" ontológico do trabalho) diante destes e demais complexos sociais (arte, cultura, política, ideologia, ciência, economia, etc.).

3) A exposição não coaduna com certas correntes do marxismo que imputam a Lukács e pecha de idealista ${ }^{5}$, ou que sua obra, notadamente Para uma Ontologia do Ser Social, seria mais uma construção metafísica. Por vezes, esse tipo de concepção tenta justificar a crítica endereçada a Lukács através de subterfúgios calcados geralmente em uma "leitura semântica" sobre o uso parcial ou a ausência completa do termo "ontologia" na textualidade marxiana. O resultado é a negação do caráter inovador da ontologia materialista proposta por Lukács "entendida" por certos críticos como "prisioneira do mundo abstrato das ideias", ou, para usarmos um termo caro aos pós-modernos, uma "metanarrativa" ultrapassada da modernidade.

O debate sobre a ontologia, contudo, como lembra Reis (2012), não está livre de polêmicas, e há dentro da Geografia contrárias, "que rejeitam

${ }^{5}$ Especialmente, mas não só, por sua polêmica obra: "História e consciência de classe"(de 1923). 
abertamente a legitimidade da reflexão ontológica no debate teórico atual" (REIS, 2012, p. 6). O problema maior é que em determinadas rejeições por vezes a defesa à um suposto marxismo trata a ontologia de modo pejorativo, desqualificando-a. É o que parece fazer Carlos (2011, p. 27) ao expor que: o marxismo "reclama o deslocamento da análise do plano da ontologia, e também do plano da epistemologia- prisioneiros do mundo abstrato das ideias" [...] "para aquele que articula a teoria (plano da produção do conhecimento como ato de compreensão do mundo) e a prática (práxis) em sua indicissociabilidade".

Apressadamente, nesse tipo de posição, com suposto apoio na teoria marxiana se reverte em afirmações categóricas sobre uma suposta "ontologia do trabalho" ou uma "centralidade do trabalho" em Lukács que este autor atribuiria à Marx, equalizando as análises de ambos sobreo tema. Nesta direção, não é incomum na Geografia, quando esta centra a análise ontológica na categoria do trabalho com base nas elaborações de Lukács, que tal incorporação seja pauta em afirmações validadas por meio de referências nem sempre consistentes, geralmente reproduzidas a partir de outros trabalhos, sem recorrer à textualidade lukasciana e, particularmente, à Ontologia do ser social do autor.

Desse modo, cabe insistir na impostação da atividade produtiva como categoria fundante ou, seja, em reforçar a posição do lugar do trabalho na Ontologia como subsidio ao debate Geográfico. Ademais, nos parece decisivo ao mesmo indicar ao final, a questão que, a nosso ver, tem sido marginalizada e, por vezes negligenciada, que é o problema da superexploração da força de trabalho na "periferia" do capital, marcada pela dependência. Visto que a superexploração, nos termos de Marini, é o fundamento do capitalismo dependente ${ }^{6}$ (MARINI, 2005).

\footnotetext{
${ }^{6} \mathrm{O}$ tratamento da categoria superexploração da força de trabalho também aparece, por vezes, de modo genérico e sem maiores explicações sobre o seu significado.
} 
Deste ponto de vista, ou seja, desta situação/condição peculiar como marca determinante (determinada) indelével da economia dependente, pode-se considerar a "centralidade do trabalho" no capitalismo dependente, demarcando, ao mesmo tempo, o problema do desenvolvimento desigual, da divisão internacional do trabalho e especificidade/particularidade que consubstancia esta formação econômico-social Logicamente, essa última consideração, demanda um salto de nível na análise necessário para delimitar a validade e vigência do trabalho no capitalismo central e periférico e, portanto, seus desdobramentos espaciais e territoriais.

O "LUGAR" ONTOLÓGICO DO TRABALHO NA TOTALIDADE SOCIAL: O PÔR TELEOLÓGICO COMO VÍNCULO ONTOLÓGICO NA RELAÇÃO SOCIEDADENATUREZA

Por vezes, no afã de contrapor-se às teses do "fim do trabalho", teses estas cujo impacto no meio acadêmico parece ainda não ter sido investigado), assumese a priori a "centralidade do trabalho" em Marx (2004, 2013) e em Lukács (2012, 2013) quase como um suposto auto evidente, mesmo que tal centralidade não seja rigorosamente investigada e qualificada. Nota-se entre uma ala da Geografia, por exemplo, a insistência nesse tipo de atribuição, inclusive tomando-o como "ponto de partida geográfico na explicação da sociedade contemporânea", arriscando-se assim, num procedimento científico um tanto quanto problemático.

O problema básico do ônus da prova, que pertence a quem adota e reproduz uma noção vaga e até vulgarizadora da centralidade do trabalho, tem sido justificado, com frequência, por meio de uma indiscutível blindagem atrás de autores clássicos como Marx (2004, 2013) ou Lukács (2012, 2013).

Chama a atenção como certos segmentos da geografia, ou seja, aqueles que procuram entender a Geografia do "mundo do trabalho", identificam em Marx, Engels ou Lukács a "centralidade do trabalho" como uma espécie fato consumado, cuja validade adquire status de ideia-força servindo como 
contraponto às teses do "fim do trabalho" (que também podem ser entendidas como sendo teses dá "não-centralidade do trabalho"). Infelizmente, neste tipo de procedimento primeiro se assume as ideias (geralmente imputadas) como verdades absolutas nestes autores, para daí se se construir contraposições à estas mesmas ideias. Esse tipo de armadilha é relativamente comum em relação ao marxismo que frequentemente se vê tendo que se defender por imputações indevidas ou deformações completas, como, por exemplo, a atribuição de determinista econômico a Marx.

A crítica aos adeptos do "fim do trabalho", desse modo, aparece entre setores da geografia crítica como um combate ao espantalho criado por opositores que, primeiro atribuem de maneira estratégica um tipo bem característico de centralidade do trabalho à Marx (Engels ou Lukács) para depois se voltarem contra ela. E isso vale também para outras atribuições vulgarizadoras. A armadilha, nesse caso, como alertou corretamente Fortes (2016, p. 46), é a “[...] de assumir os argumentos da questão daquele a quem se busca criticar" e, no limite, terminar por “aceitar a própria natureza do problema posto pelo antagonista, deixando de realizar a compreensão da sua dimensão efetiva" (Idem, ibidem).

O rebate crítico necessário às teses do fim do trabalho apoia-se, não raro, em procedimentos que procuram a todo custo extrair de Marx e de outros marxistas as "provas" para reafirmar a importância de um formato de centralidade do trabalho imputada ao pensador revolucionário, facilitando assim o caminho para o ataque ideológico antimarxista, cuja intenção é banalizar a complexidade do legado de Marx facilitando a "desconstrução" de seu pensamento. Assim reduzido à um "conjunto de teses simples e de difícil sustentação, a destituição do pensamento de Marx é feita de modo direto e aparentemente coerente" (FORTES, 2016, p. 46). 
Problema maior é quando a Geografia - em sua linha que investiga o trabalho, por exemplo, apoia-se numa certa corrente da Sociologia do trabalho, visando com isso, tentar combater as teses dos pensadores do "fim do trabalho". O que infelizmente ocorre nestes casos é que se acaba por cair na armadilha da reprodução, consciente ou não, dos “[...] argumentos daqueles a quem se visa combater - seus conceitos, assim como a forma da colocação do problema - para defender a ideia contrária" (FORTES, 2016, p. 46).

Ao fazer isso, corre-se o risco de assumir os argumentos daqueles a quem se busca criticar, isto é, acatar o problema posto pelo oponente sem verificar a efetividade da dimensão que se procura analisar. Esse procedimento pode ainda descambar para aceitação da "centralidade do trabalho" como uma noção marxiana ou marxista inquestionável sem uma verificação profunda de sua ocorrência. Tal movimento, questiona corretamente Fortes (2012, p. 46) “não seria compactuar com as próprias interpretações enviesadas desses autores, perdendo desse modo o caráter da especificidade da análise dos pensadores a quem se busca defender, nesse caso, Lukács e Marx?".

Que o combate às teses sobre o "fim do trabalho"7 não só deve, mas precisa ser feito tendo Marx e Lukács como ponto de entrada para a crítica, de modo retomar criticamente os traços gerais de suas descobertas e atualidade da maioria destas, aliando estes às análises das novas determinações surgidas das contradições do capital e, por conseguinte, de seus desdobramentos espaciais, não parece restar dúvidas. Por isso mesmo, as categorias como o trabalho devem ser postas ao crivo da crítica radical.

Desse modo, concordamos do Fortes (2016), quando escreve que apresentar uma contraposição simplista aos adeptos da "não centralidade" do

\footnotetext{
${ }^{7}$ Mesmo que a sociedade estivesse rumando para uma situação na qual o trabalho deixasse de ter importância na reprodução social, o que colocaria em xeque a própria reprodução do capital, a intervenção crítica de Marx ou de Lukács não seriam abaladas pelas transformações ocorridas: ao contrário, a importância da intervenção destes autores, na verdade, seria realçada.
} 
trabalho "sob a forma de jargões ideológico-políticos mal elaborados serve apenas para alimentar a sanha e as armas do inimigo contra aquilo que se busca defender" (FORTES, 2016, p. 47). A contraposição simplista e/ou vulgar, portanto, só fortalece o inimigo que se pretende combater, facilitando assim, o caminho para os teóricos que visam não só "descontruir" o que eles identificam como sendo "trabalho" e o "trabalhador" em Marx ou em Lukács, mas o próprio papel destas categorias, bem como das classes e, particularmente, do proletariado, como ponto de apoio para a compreensão e transformação revolucionária.

Nesse sentido, como apontou o mesmo Fortes (2016, p. 68), faz-se necessário uma posição (e oposição) crítica atenta às dimensões (gerais e particulares) histórico-ontológicas da categoria trabalho, notadamente em autores como Lukács (2012, 2013), as quais permitam lançar luz ao “lugar correto” deste complexo social mediador na produção do espaço geográfico em meio aos demais complexos do ser social, e deste modo tentar contribuir para uma apresentação da peculiaridade ontológica desta categoria dentro da totalidade social.

O caso de Lukács (2012) talvez possa ajudar nesse sentido, pois a este autor costuma-se imputar um formato de centralidade do trabalho avessa ao que sua obra, notadamente a da maturidade, apresenta. Por isso, como exemplo, cabe retomar alguns pontos já indicados por Fortes (2016) sobre o papel do complexo do trabalho na Ontologia do Ser Social de Lukács, visto que a noção de centralidade recuperada com frequência por uma parte da Geografia crítica advém de leituras da Ontologia (ou de parte da Ontologia) (FORTES, 2016).

Reivindicar o "lugar do trabalho" no quadro da ontologia do ser social de Lukács $(2012,2013)$ e, por conseguinte, seu papel de suma importância no que se refere às análises geográficas, é, também, uma forma de apontar para o velho problema da peculiaridade ontológica desta mediação no processo complexo de transformação da natureza e do próprio ser social. 
Ao mesmo tempo, retomadas nestes moldes são necessárias para trazer para o primeiro plano o problema das condições e determinações materiais da vida socialenvoltas em camadas de processos objetivos e subjetivos que "afastam o ser social de suas barreiras naturais" (LUKÁCS, 2012, 2013). (Re)colocar o problema do trabalho em perspectiva geográfica e crítica implica ainda atentar para o do papel da força de trabalho sob o capitalismo, vendida "livremente", mas também explorada e superexplorada ${ }^{8}$. Disso resulta também o problema do estranhamento, e nesse ponto a demarcação ontológica de Lukács é fundamental devido ao seu caráter histórico dessa dimensão sob o capitalismo. Como bem lembrou Fortes (2016), a passagem corriqueira que procura sustentar a noção de centralidade em Lukács seria esta:

No momento em que Marx faz da produção e da reprodução da vida humana o problema central, surgem, tanto no próprio ser humano como em todos os seus objetos, relações, vínculos etc. como dupla determinação de uma insuperável base natural e de uma ininterrupta transformação social dessa base. Como sempre ocorre em Marx, também nesse caso o trabalho é a categoria central [zentrale Kategorie], na qual todas as outras determinações já se apresentam in nuce (LUKÁCS, 2012, p. 285).

No entanto, se lido com cuidado o trecho remete especificamente à importância do trabalho na consideração dos complexos da produção e reprodução. Daí que [...] "ainda que se quisesse insistir na ideia da centralidade, esta única passagem não seria argumento suficiente para sustentar a hipótese" (FORTES, 2016, p. 46). De fato, uma “hipótese de tal natureza precisaria no mínimo demonstrar a ancoragem de toda a reflexão lukacsiana tendo como centro o trabalho, ou seja, nos moldes em que costumeiramente se dá a imputação desse

\footnotetext{
${ }^{8}$ No caso de uma formação econômico-social "periférica" como é o caso do Brasil, como veremos adiante, o problema refere-se à questão da superexploração da força de trabalho.
} 
conceito às reflexões de Lukács" (FORTES, 2016, p. 46 itálicos nossos). Portanto, o argumento da centralidade é bastante frágil se referido à Lukács.

Para melhor visualizar a posição de Lukács sobre o trabalho, recorremos a alguns dos princípios que regem este complexo e o diferencia (qualitativa e hierarquicamente) dos demais. Distinções qualitativas e hierárquicas que não tem a ver com uma mera posição valorativa, pois "o trabalho é antes de tudo, em termos genéticos, o ponto de partida para tornar-se [devir] homem do homem, para a formação das suas faculdades, sendo que jamais se deve esquecer o domínio sobre si mesmo" (LUKÁCS, 2012, p. 348). Além do mais, o trabalho se apresenta, "por um longo tempo, como o único âmbito desse desenvolvimento; todas as demais formas de atividade do homem, ligadas aos diversos valores, só se podem apresentar como autônomas depois que o trabalho atinge um nível relativamente elevado" (Ibidem).

Esse procedimento é claramente didático e não sem riscos de também reduzir a complexidade dado por Lukács $(2012,2013)$ ao trabalho e os complexos localizados no interior do processo de trabalho, portanto servem tão somente como guia de apresentação (não sem o risco da simplificação). Neste sentido, o tratamento dado pelo autor ao pôr teleológico parece ser um parâmetro necessário, visto que a identificação precisa deste complexo ontológico no interior do processo de trabalho é um dos traços fundamentais da caracterização de uma ontologia materialista. Ademais, ele "nos permite vislumbrar a forma mais geral de toda atividade do homem, seja junto à natureza, seja nas formas superiores da práxis social" (FORTES, 2016, p. 49).

Lukács (2013, p. 47) referindo-se ao pôr teleológico no trabalho assinala que este é "[...] a categoria ontológica central do trabalho". Portanto, aqui o autor se refere àquilo que é central no trabalho, já que é destes pôres que se realiza, no âmbito do ser material, novas objetividades. Assim, escreve ainda Lukács, o trabalho se torna o "modelo de toda práxis social, na qual, com efeito - mesmo 
que através de mediações às vezes muito complexas -, sempre se realizam pores teleológicos, em última análise, de ordem material" (Ibidem).

Ao mesmo tempo o autor alerta, que “[...] não se deve exagerar de maneira esquemática esse caráter de modelo do trabalho em relação ao agir humano em sociedade"; precisamente porque a consideração das diferenças bastante importantes "mostra a afinidade essencialmente ontológica, pois exatamente nessas diferenças se revela que o trabalho pode servir de modelo para compreender os outros pores socioteleológicos, já que, quanto ao ser, ele é a sua forma originária" (Idem, ibidem).

Os pôres teleológicos surgem inicialmente com o trabalho enquanto procedimentos conscientes postos em prática na apropriação e transformação da natureza e cujo resultado (pré-ideado ${ }^{9}$ ) ganha efetividade concreta nas múltiplas formas de objetivação. Desse modo, segundo Lukács (2012), a categoria ontológica central "do" trabalho, isto é, o por teológico, aparece como determinação primeira da práxis do ser social, anunciando, portanto, a “determinação daquilo que Lukács designa como modelo [mode/] que não se confunde de modo algum com a ideia do trabalho como centralidade de toda prática humana" (FORTES, 2016, p. 48). "Modelo significa que, nessa primeira práxis identificável do ser social, já se encontra presente a caracterização mais geral de toda atividade humana, a de ser um pôr teleológico" (Idem, ibidem, p. 48).

A capacidade humana de projetar na mente, de dar uma finalidade ao seu projeto e, portanto, agir criativamente no mundo, transformando a natureza para atender suas necessidades, construindo assim (a sua própria) história, via trabalho, é um pressuposto ontológico básico ligado às necessidades sóciohistóricas próprias do ser social. O que estabelece a distinção fundamentalentre

\footnotetext{
${ }^{9}$ Condição imprescindível do processo de trabalho, a prévia-ideação prenuncia aquilo que se pretende objetivar-exteriorizar. Neste sentido, escreve Lukács (2013, p. 48), com o pôr, "a consciência dá início a um processo real, exatamente ao processo teleológico. Assim, o pôr tem, nesse caso, um caráter irrevogavelmente ontológico".
} 
a "atividade" realizada pelo ser natural e aquela realizada pelo ser social no interior da unidade entre ambos os complexos, é que este último produz, primeira e verdadeiramente, na [sua] liberdade [com relação] a ela e, por meio dessa liberdade, defronta-se livremente com o produto objetivado (conscientemente) no e pelo trabalho (MARX, 2004, p. 85).

Teleologia, no entanto, não significa um processo fechado ou num ato determinista e/ou finalista por si só. Ao contrário, há, apesar da aparente contradição, um entrelace dialético entre teleologia e causalidade, esta última "um princípio de automovimento que repousa sobre si próprio e mantém esse caráter mesmo quando uma cadeia causal tenha seu ponto de partida num ato da consciência [...]" (LUKÁCS, 2013, p. 48).

Ambas dimensões formam uma "unidade dos contrários" no interior do processo de trabalho. Visto que, de acordo com Lukács (2013, p. 52) existe, inevitavelmente, uma coexistência concreta, real e necessária entre causalidade e teleologia. A aposição entre ambas ocorre, portanto, apenas no interior de um “processo real e unitário, cuja mobilidade é fundada na interação desses opostos e que, para tornar real essa interação, age de tal modo que a causalidade, sem ver atingida a sua essência, também se torna posta" (LUKÁCS, 2013, p. 52).

Nessa direção, como pontua Lukács, (1978), é decisivo compreender que se está em face de uma duplicidade. Isso porque, se numa sociedade determinada a maior parte das atividades cujo conjunto põe a totalidade em movimento é certamente de origem teleológica, a "sua existência real - e não importa se permaneceu isolada ou se foi inserida num contexto - é feita de conexões causais que jamais e em nenhum sentido podem ser de caráter teleológico" (LUKÁCS, 1978, p. 6). Em suma,

[...] a atividade laborativa é compreendida como a ação consciente sobre o elemento natural, mediante a capacidade de reconhecer as propriedades e os princípios do movimento da legalidade da natureza. Ao apreender os nexos da malha causal, ao 
assumi-los na consciência por meio da reprodução ideal, o homem torna-se capaz de transformar a matéria natural, produzindo, desse modo, um objeto apto a satisfazer suas necessidades e carências. O trabalho aparece, desta forma, como a unidade do pôr efetivo de um dado produto e da prévia ideação dos nexos causais da natureza, mediada e dirigida pela finalidade previamente estabelecida (FORTES, 2016, p. 50).

Inscrito nas entrelinhas do processo de trabalho, os atos teleológicos ligados aos nexos causais da natureza imprimem um caráter cada vez mais intrincado à sociabilidade, dada a ampliação do rol da rede de novas objetivações que "desenvolvem-se segundo certos nexos causais, com ações recíprocas em seu interior e ações recíprocas de um complexo em relação ao outro" (LUKÁCS, 2013, p. 86). Assim, as formas superiores da prática social, ainda que contenham os traços mais gerais não podem ser reduzidas a estes, ao contrário, diante do processo de desenvolvimento humano ocorre o predomínio de pores teleológicos qualitativamente distintos daqueles presenciados no trabalho.

A distinção “[...] consiste no 'objeto' ou na 'matéria' sobre a qual a finalidade visa a intervir" (FORTES, 2016, p. 51). Daí Lukács estabelecer a diferença entre pores primários e pores secundários, donde os segundos não estão voltados à imediata ação de transformação da natureza, mas "apresentam como finalidade imediata a intenção de conduzir outros homens a assumir determinadas ideias e comportamentos ideados previamente por aqueles que objetivam induzir a ação desses" (FORTES, 2016, p. 51).

Neste sentido, apesar (e por causa) de determinados atos teleológicos, quanto mais se desenvolve o ser social, mais suas objetivações transcendem o espaço ligado diretamente tanto mais se desdobra e se amplia o espaço do rol categorial, ou seja, verifica-se "a ampliação e a autonomização das categorias e dinâmicas intrínsecas ao complexo originário, assim como o surgimento de novas categorias que determinam a especificidade das formas superiores" (FORTES, 2016, p. 51). 
Diante dos processos teleológicos, diferenças específicas surgem a partir dos traços mais gerais do processo de desenvolvimento social ("descontinuidades na continuidade"), de modo que novos patamares são alcançados pelo "afastamento..." das barreiras naturais rumo à sociabilidade. Nessa medida, o “desenvolvimento do ser social é marcado pelo sempre crescente predomínio das categorias sociais puras, que passam a vigorar de maneira decisiva no curso dos desdobramentos deste complexo de ser" (FORTES, 2011, p. 95). Desse modo,

[...] com os desdobramentos e com o surgimento das formas ulteriores da prática social verifica-se a ampliação e a autonomização das categorias e dinâmicas intrínsecas ao complexo originário, assim como o surgimento de novas categorias que determinam a especificidade das formas superiores. Estas últimas entram em ação e se realizam por meio da "crescente diferenciação" das formas originárias da prática social, criando um distanciamento significativo em relação à estrutura genética do pôr teleológico presente no trabalho (FORTES, 2016, p. 51).

Assim, não se podem deduzir, por exemplo, as relações sociais mais complexas a partir de uma suposta centralidade do trabalho que não reconhecida nestes termos do emaranhado qualitativo e distintivo envolvendo tantos os processos "internos" do trabalho quanto a dimensão de relação "externa” com a natureza ontológicos, pois com esclarece Fortes (2016, p. 56): nas formas “superiores da sociabilidade os traços mais gerais do pôr teleológico se encontram sobredeterminados, sobreconformados pela mediação de novas categorias que surgem no decurso de desenvolvimento do ser social".

\section{RELAÇÕES CATEGORIAIS: A CENTRALIDADE DO TRABALHO COMO PRIORIDADE ONTOLÓGICA}

Fortes (2016, p. 57), destacando as importantes contribuições de Lukács no que tange às relações categoriais, expõe que a "disposição" entre estas obedece não apenas a coordenação paritária, isto é, os elementos não se apresentam somente de modo reflexivo dentro da unidade de complexos, mas assumem, 
também, uma configuração de sobreordenação e subordinação(LUKÁCS, 2012, p. 307). A primeira,

[...] confere o reconhecimento de papel preponderante de dadas categorias no interior do complexo, que subordina outras categorias, dando-Ihes a diretriz decisiva na condução do processo. Isso significa que as relações existentes entre categorias não são da mesma ordem, relevância e grau. Quanto à sobreordenação, podemos dizer que ela possui um duplo caráter: dada categoria pode aparecer como elemento mais decisivo na condução do processo e da dinâmica do complexo (momento preponderante), ou mesmo como elemento que atua como pressuposto necessário para a existência de outras categorias (prioridade ontológica). Quanto ao segundo princípio, podemos dizer que seu caráter de pressuposto necessário confere a um elemento a prioridade ontológica sobre os outros elementos que somente podem vir a existir apoiados sobre este. Sua prioridade consiste na demarcação da ordem de sucessão das categorias, nas palavras de Lukács, ao fato ontológico decisivo, segundo o qual 'a primeira pode existir sem a segunda, enquanto o inverso é ontologicamente impossível'.

Dentro deste intrincado quadro categorial, a prioridade significa uma demarcação no ordenamento ontológico das categorias a qual implica num fato ontológico fundamental e decisivo, isto é, certas categorias não podem existir sem outras enquanto o inverso é ontologicamente impossível. Não é a consciência que determina o ser, mas o ser que determina a consciência. Esse princípio materialista elementar sinaliza para o fato de que a disposição relacional entre as categorias não é de mesma ordem, relevância e grau (LUKÁCS, 2013; FORTES, 2016).

Além do mais, escreve Lukács (2012, p. 297), “[...] as categorias não são elementos de uma arquitetura hierárquica e sistemática", mas ao contrário, na realidade são "formas de ser, determinações da existência” (MARX, 2011, p. 69), "elementos estruturais de complexos relativamente totais, reais, dinâmicos, cujas inter-relações dinâmicas dão lugar a complexos sempre mais abrangentes em sentido tanto extensivo quanto intensivo" (LUKÁCS, 2012, p. 245). 
Categoria, neste sentido, conforme esclarece Fortes (2012, p. 95), é “[...] sempre a expressão da forma do ser e encontra-se determinada pela existência concreta do complexo". Assim, "o elemento ou categoria não possui uma natureza autônoma, independente e perene", quer dizer, "características fixas que se reproduzem e operam sempre por meio das mesmas diretrizes independentemente do complexo em que atuam" (Idem, ibidem). A compreensão das categorias, sob esta perspectiva, "deve se dar por meio da especificação de seu processo real de interação com outros elementos, sempre analisados na particularidade do contexto e da situação em que ele se apresenta" (Idem, ibidem).

No que tange, por exemplo, à categoria trabalho enquanto produtora de valor de uso, verifica-se que esta tem prioridade ontológica sobre determinadas categorias, isso porque, o desenvolvimento do ser social pressupõe a mediação com a natureza, num movimento dialética (sociometabólico, como indicou Marx) que é, ao mesmo tempo, produção da natureza (SMITH, 1988) e (re)produção do ser social. Tal vinculo ontológico (ser social e natureza) é marcado pela apropriação (que pode ser social ou privada) do(s) território(s). O fato é que tais processos se concretizam objetivamente por meio do "ordenamento" ontológico das categorias, de maneira que:

A prioridade ontológica é atribuída à relação necessária entre o homem e a natureza como forma de produção e reprodução da própria vida, ou seja, a categoria social valor somente se efetiva no ato da reprodução que envolve necessariamente a relação entre o homem e a natureza, expressa de forma mais imediata na categoria valor de uso. Trata-se, pois, de uma realização que não pode prescindir da anterioridade das efetivações materiais, mas que apresenta como diretriz preponderante do processo de desenvolvimento do ser social a categoria valor. O valor, determinado como momento preponderante da esfera econômica na forma peculiar da sociabilidade do capital, surge apoiado sobre o valor de uso, possui esta base como seu pressuposto, mas se torna no interior das relações humanas a categoria decisiva, de onde se originam as diretrizes sobre as quais se encontram 
emaranhados os elementos que dinamizam o curso do processo social (FORTES, 2013, p. 153).

O valor, dentro desse movimento ontológico e histórico, não é, portanto, um mero produto derivado diretamente das categorias próprias do trabalho ou da economia, mas "[...] passa a existir no âmbito do trabalho sobredeterminado, no contexto de interações com os outros complexos da totalidade social" (FORTES, 2016, p. 60). Por isso, o alerta de Lukács (2013) é claro: uma coisa é dizer que todo fenômeno social pressupõe "[...] o trabalho com todas as suas consequências ontológicas" (LUKÁCS, 2013, p. 159); outra, bem diferente, é tentar derivar diretamente todas as formas de práxis social ${ }^{10}$ do trabalho.

Ademais, a "condição" do trabalho dentro da totalidade social, mantem seus traços gerais (continuidade com elementos de descontinuidade), mas ainda assim ganha novas determinações diante das interações com os demais complexos sociais, de modo que a "forma de sua realização histórica apresenta transformações significativas, que devem ser analisadas na especificidade de sua efetivação" (FORTES, 2016, p. 69). É por isso que as alterações no que alguns denominam "mundo do trabalho" são, de fato, processos imanentes à processualidade histórica na qual predomina o modo de produção capitalista e sua forma valor, cujas transformações incidem sobre o trabalho que se (re)configura de modo particular na sua espacialidade diversa, "refletindo o caráter decisivo das leis tendenciais da sociabilidade na qual se realiza" (Idem, ibidem, p. 70).

Neste sentido, sem incorrer em preciosismos terminológicos, a nosso ver, uma forma mais coerente de lidar com a proposição marxiana sobre o trabalho na Geografia é precisar a categoria como um complexo de complexos do ser social fundamental no processo de reprodução, ou seja, de modo algum trata-se de

\footnotetext{
${ }^{10}$ A categoria de práxis em sentido ontológico, portanto, permite apreender a riqueza material e simbólica do ser social em seu vir-a-ser, isto é, para além das objetivações primárias.
} 
negar a importância do trabalho com protoforma da práxis humana, ou seja, modelo ${ }^{11}$ objetivamente ontológico de toda práxis social (LUKÁCS, 2013), mas sim de “[...] colocá-lo em seu devido lugar na análise, isto é, explicitar o seu caráter de base ontológica fundamental, sua função de prioridade ontológica" (FORTES, 2016, p. 70) sempre tendo em vista que esta categoria (parcial ${ }^{12}$ ) possui um lugar na dinâmica da totalidade social e, por conseguinte, no processo de (re)produção (LUKÁCS, 2013, p. 156-157). Por isso Lukács (2013, p. 278), pontua:

[...] o ser social é um complexo composto de complexos, cuja reprodução se encontra em variada e multifacetada interação com o processo de reprodução dos complexos parciais relativamente autônomos, sendo que à totalidade, no entanto, cabe uma influência predominante no âmbito dessas interações

As complexas mediações envolvendo as categorias sociais (e suas relações com a dimensão natural) tem no trabalho um "determinante determinado" vinculadas ao princípio elementar que se refere ao atendimento das necessidades humanas (no "reino da necessidade") e, por conseguinte, à reprodução históricogeográfica do ser social (de onde surgem as possibilidades concretas de alcançar o "reino da liberdade"13). Por isso, dizer que "[...] todo fenômeno social pressupõe [...] o trabalho com todas as suas consequências ontológicas" (LUKÁCS, 2013, p. 159) não significa de maneira alguma “[...] atribuir a essa categoria um determinismo unívoco de todas as outras esferas e dimensões da práxis social, muito menos compreender as práticas superiores do ser social como simples

\footnotetext{
11 No entanto, alerta o próprio Lukács (2013, p. 47): “[...] não se deve exagerar de maneira esquemática esse caráter de modelo do trabalho em relação ao agir humano em sociedade". Ou, como pontua Fortes (2016, p. 48): "Se o trabalho oferece os traços mais gerais de toda atividade humana, são, na verdade, as diferenças especificas que determinam a peculiaridade de cada atividade, e não seus traços em comum".

${ }^{12}$ Que "é determinada não só pela legalidade própria do complexo parcial, mas simultaneamente e sobretudo também por sua posição e função na totalidade social" (LUKÁCS, 2013, p. 306).

13 "Para Marx, o mundo da economia (que se chama de 'reino da necessidade') será sempre, ineliminavelmente, a base daquela automação do gênero humano que se define como 'reino da liberdade"' (LUKÁCS, 2008, p. 112 apud FORTES, 2016, p. 72).
} 
prolongamentos complexificados dessa base" (FORTES, 2016, p. 68). Por 'pressuposto' deve-se entender que todas as outras formas da prática humanosocietária não podem prescindir dessa base ontológica elementar, aliás, responsável pela materialização ou produção do espaço, ou seja, as demais práticas, processos e objetivações, assentam-se sobre o tralho, realizam-se apoiados sobre esse "lugar" que sustenta estes demais complexos que, de modo algum, são simples derivados do trabalho.

Em suma, o "lugar" ontológico do complexo do trabalho enquanto forma originária de toda práxis do ser social, assim como as relações e inter-relações (reflexivas) entre as categorias (em reciprocidade dialética) e cuja prioridade ontológica está assentada ineliminavelmente no "reino da necessidade", não pode ser equalizado à uma proposição banal ou superficial de "centralidade do trabalho" se esta se referir a autores do porte de Marx ou de Lukács. Cabe, portanto, asseverar sobre o cuidado no trato de um tema dessa envergadura ainda mais no que se refere à Geografia crítica. Afinal, como afirmou certa vez Palmiro Togliatti (1893-1964): "quem erra na análise, erra na ação".

PARA (NÃO) FINALIZAR

O esboço acima não tem a intenção de ser a explicação definitiva e, menos ainda, dar por encerrado um assunto de tamanha complexidade, ainda mais em se tratando de um autor da estatura de Lukács. Tratou-se tão somente de retomar e apontar (e, em certa medida, reafirmar), o "lugar" ontológico e histórico do trabalho, categoria fundamente do ser social e mediação fundamental na produção do espaço, sendo, portanto, de suma relevância para a Geografia e para o marxismo. Daí retomarmos com certo rigor os apontamentos feitos por Fortes (2016) sobre o trabalho na obra madura de Lukács

Ao recorremos a Lukács $(2012,2013)$ e Fortes (2016) tentamos sinalizar (e alertar) sobre o problema da adoção (e até imputação) acrítica de uma suposta 
“centralidade do trabalho" a Lukács (e arriscaríamos dizer, a Marx), sem que se comprove tal centralidade. Tal procedimento, que geralmente parte de alguns capítulos tanto da obra de Marx (notadamente O Capital, livro 1) e o capítulo do trabalho da Ontologia de Lukács, sem que se considere a abrangência da obra de ambos, assim como, no caso de Lukács, o tratamento dado às relações e desenvolvimento categorial que o autor procura traçar, seguindo os passos de Marx.

Dito isso, cabe finalizar apontando para uma outra direção! Para uma outra diferencia específica!

Saltando de um nível de análise a outro, é válido ao menos sinalizar para uma outra direção no que se refere ao papel do trabalho, seguindo as trilhas da TMD. Em outras palavras, trata-se de apontar para a "centralidade do trabalho" do ponto de vista da inserção subordinada da força de trabalho brasileira na economia nacional dentro da Divisão Internacional do Trabalho, o que remete à condição de superexploração que é própria desta economia dependente.

Em outros termos, se uma discussão sobre a produção do espaço remete ao papel do trabalho como elemento fundamente da totalidade social (concreta, aberta e histórica num sentido marxiano e lukasciano), o desenvolvimento do capital e do capitalismo (MÉSZÁROS, 2002) e, por conseguinte, de sua dinâmica mundial do desenvolvimento desigual, desdobra-se contraditoriamente, assumindo uma condição que imprime uma dinâmica própria às relações entre capital x trabalho, já que as burguesias recorrem aos meios mais abusivos e, no limite, mais brutais, para superexplorar a força de trabalho e assim "compensar" suas perdas (MARINI, 2005, LUCE, 2018).

Para deixarmos este alerta um pouco mais claro, mas ainda assim, de modo um tanto quanto rápido, estamos aqui reverberando Marini (2005) e Luce (2018). Para estes autores, o mercado torna-se mundial ao se expandir via a produção e circulação de mercadorias, isto é, o desdobramento didático-contraditório da 
lógica da valorização do capital para todos os rincões do mundo. Mas esse mesmo processo de expansão - que é um processo de interação - se dá através da divisão deste mercado, que se forma ampliadamente, sob esferas distintas de produção que se inter-relacionam (a divisão internacional do trabalho) (LUCE, 2018, p. 28).

A assunção/violação da lei do valor, a violação do valor contida na lei do valor (LUCE, 2018, p. 29), que ocorre nas economias dependentes, o que, por suposto, envolve uma supre de outras determinações e mediações ${ }^{14}$ da Teoria Marxista da Dependência (TMD), que não podemos retomar aqui, desdobra-se, ou melhor, compreende a especificidade/particularidade espacial do capitalismo dependente brasileiro.

Se a "superexploração é a categoria totalizante da formação socioespacial latino-americana, ou seja, é aspecto específico dessas nações [diríamos, dessas economias] dentro da unidade que consiste o modo de produção capitalista", como escreve Aruto $(2015, \text { p. } 2)^{15}$, isto é, se esta categoria é "central" neste sentido específico, ou melhor, é o fundamento do capitalismo dependente como defende Marini (2005) e outros adeptos da TMD, faz-se necessário compreender seu significado "como categoria que busca dar conta do aspecto central da reprodução do capital dependente" (OSORIO, 2009, p. 171).

Em formações econômico-sociais "periféricas", geradas pela dinâmica contraditória (desenvolvimento desigual) do capital como sistema mundial,

\footnotetext{
14 Transferência de valor com intercambio desigual, intensidade do trabalho nacional, preços, tendencias e contratendências, excedente produzido e apropriado, taxa de lucro, produtividade, importação, exportação, comércio internacional, mercador mundial, deterioração dos termos de intercambio, serviço da dívida (remessas de juros), remessas de lucros royalties e dividendos, apropriação de renda diferencial e de renda absoluta, cisão na fases do ciclo do capital (ou divórcio entre estrutura produtiva e as necessidades das massas, formação socioespacial dependente, etc. (MARINI, 2005, LUCE, 2018), são só alguns dos problemas que não podemos avançar aqui.

15 Para este autor: "A categoria de superexploração se torna o elemento totalizante dos países dependentes. É através dela que se deve partir para compreender, num plano de análise abstrato, as relações dos países com o modo de produção capitalista como um todo. Mas a superexploração se manifesta também nos mais diversos aspectos concretos dos países dependentes. Concretude que advém, [...] da contínua transformação do espaço social pela reprodução das relações de produção" (ARUTO, 2015, p. 64).
} 
encontra-se "o lugar" da categoria superexploração da força de trabalho. Esta categoria, é uma das mais fundamentais (e fundantes), porque sintetiza a dinâmica específica da (re)produção espacial do capitalismo periférico latinoamericano.

Neste sentido, a superexploração da força de trabalho por suposto, possui traços fenomênicos e formas de manifestação distintas, contudo, sua "essência" foi definida por Marini (2005, p. 189), como “maior exploração da força física do trabalhador, em contraposição à exploração resultante do aumento da produtividade", o que "tende normalmente a se expressar no fato de que a força de trabalho se remunera abaixo do seu valor real" (Ibidem), ou seja, uma remuneração abaixo do valor em condições "normais", o que afeta para pior a vida de milhões de trabalhadores(as), notadamente mulheres, negras e pobres (aquelas que ainda conseguem algum emprego ou trabalho precário).

A superexploração da força de trabalho, ao expressar e elucidar, por um lado, a existência das chamadas trocas desiguais entre economias centrais e periféricas, donde as segundas saem em desvantagens e precisam "compensar suas perdas com o brutal ataque da burguesia que atua na economia dependente via superexploração da força de trabalho" (XAVIER, 2018, p. 389), expõe o fundamento do próprio imperialismo, ou seja, “como o desenvolvimento das economias cêntricas é realizado às despensas das economias periféricas e como se dá o ciclo de reprodução do capital nas últimas" (Idem, ibidem) cujos desdobramentos territoriais resultam em graves consequências sociais e ambientais.

Dessa maneira, a existência da dependência posta nestes termos e, junto com ela, da superexploração da força de trabalho, reproduz uma dinâmica interna de manutenção de condições altamente degradantes e no limite destrutivas para o conjunto dos trabalhadores e demais grupos (indígenas, camponeses, quilombolas, etc.), daí ser o trabalho e, mais precisamente a força de trabalho, 
(junto com outras categorias como a terra, o Estado, as classes), assim como para a natureza submetida à lógica específica da dinâmica da lei do valor na economia dependente brasileira (LUCE, 2018).

Assim, se a complexidade da formação econômico social é determinada (e determina) as condições de reprodução espacial e, concomitantemente, esta formação e seu espaço são "produtos" de determinadas relações de trabalho sob o capitalismo dependente, a superexploração da força de trabalho, como parte constitutiva destas relações, incide, perpassa, molda e estrutura de modo significativo estas relações, as quais, por sua vez, consubstanciam as formas de resistência e lutas, bem como seus limites e potencialidades.

Para além das proposições sobre o "fim do trabalho", bem como daquelas posições que vulgarizam ou descartam a categoria na compreensão de certos aspectos da dinâmica espacial e territorial, ou ainda outras que pregam uma noção de "centralidade do trabalho" sem o devido rigor teórico, etc., cabe reafirmar a validade do trabalho enquanto categoria ontológica, histórica e geográfica. Essa reafirmação, contudo, a nosso ver, poder ganhar ainda mais densidade se reconhecida em sua dimensão "periférica", ou seja, enquanto categoria fundamente do capitalismo dependente (MARINI, 2005). E aqui cabe sinalizar não só para "papel econômico" da categoria, mas fundamentalmente sua especificidade na luta de classes e na política.

A superexploração da força de trabalho enquanto parte do trabalho (e dos trabalhadores) da periferia do capital, é parte constitutiva das tendências da dinâmica capitalista e, nesse caso, onde as condições de classe e de luta de classes estão assentadas em contradições e processos que tendem a ser mais agudizados do que nos centros.

Assim, a periferia é também lócus de possibilidades virtuais de lutas transformadoras radicais e revolucionárias, cujas mediações e determinações (especificas e particulares) apontam para uma outra forma de "centralidade do 
trabalho", se se quiser usar estes termos. Nesse sentido, reafirmando o óbvio, mas nem por isso menos importante: uma Geografia crítica ligada ao “mundo do trabalho" deve continuar atenta às especificidades estruturais e sistêmicas e as transformações conjunturais da "periferia" do capital.

Esse brevíssimo destaque final sobre o capitalismo dependente aponta, evidentemente, para a figura do trabalho e dos trabalhadores superexplorados, cujo "lugar" na periferia demanda um contínuo e renovado esforço de análise amparado numa crítica rigorosa e numa práxis radical que contribuam com as lutas pela superação do capitalismo e, portanto, do próprio trabalho em sua forma superexplorada e estranhada.

\section{REFERÊNCIAS BIBLIOGRÁFICAS}

ANTUNES, Ricardo. Adeus ao trabalho? Ensaio sobre as metamorfoses e a centralidade do mundo do trabalho. São Paulo, Cortez, 1995.

Os sentidos do trabalho. São Paulo, Boitempo Editorial, 1999.

ARENDT, Hannah. A Condição Humana. São Paulo, Forense Universitária, 1981.

ARUTO, Pietro Calderini. A formação socioespacial dependente a partir da superexploração da força de trabalho: uma abordagem metodológica. Dissertação Mestrado. Campinas, SP, 2015.

AZNAR, Guy. Trabalhar menos para trabalharem todos. São Paulo: Scritta, 1995.

BITETI, M. de O. Uma reflexão sobre o tema da ontologia na geografia. 2007. 174

f. Dissertação Mestrado em Geografia - Programa de Pós-Graduação em Geografia, Universidade Federal Fluminense, Niterói, 2007.

CARCANHOLO, Marcelo Dias. O atual resgate crítico da teoria marxista da dependência. In: Trab. Educ. Saúde, Rio de Janeiro, v. 11 n. 1, p. 191-205, jan./abr. 2013.

CARLOS, A. F. A. A Condição Espacial. São Paulo: Editora Contexto, 2011.

A "Geografia Crítica" e a crítica da Geografia. Scripta Nova. Revista Electrónica de Geografía y Ciencias Sociales. Barcelona: Universidad de Barcelona, 
1 de agosto de 2007, vol. XI, núm. 245 (03). Disponível em: http://www.ub.edu/geocrit/sn/sn-24503.htm. Acesso em: 01-12-2021.

CAVALCANTI, H. B. O surgimento e a importância da Geografia do Trabalho. In: Revista Pegada - vol. 21, n.2. Maio-Agosto, p. 85-100, 2020.

FORTES, Ronaldo Vielmi. Trabalho e gênese do ser social na Ontologia de Georg Lukács. Dissertação Mestrado. Universidade Federal de Minas Gerais (UFMG), Belo Horizonte, 2001.

- György Lukács e a inflexão da ontologia. Ser, objetividade e história no pensamento de Karl Marx. Verinotio, Belo Horizonte, n. 13, v. 2, p. 90-100, 2011.

As novas vias da ontologia em György Lukács: as bases ontológicas do conhecimento. São Paulo: Novas Edições Acadêmicas, 2013.

- As três determinações fundamentais da análise lukacsiana do trabalho: modelo das formas superiores, prioridade ontológica e abstração isoladora Crítica da ideia da centralidade do trabalho em Lukács. Verinotio, Belo Horizonte, n. 22, p. 44-75, 2016.

FRANCESCONI, Léa. Trabalho, tema da pesquisa geográfica. In: Revista Pegada Eletrônica. V. 1 e 2, UNESP Presidente Prudente, 2006.

GEORGE, Pierre. Sociologia e geografia. Rio de Janeiro: Forense, 1969.

GORZ, André. Adeus ao proletariado: para além do socialismo. Rio de Janeiro: Forense - Universitária, 1987.

- Metamorfoses do trabalho - crítica da razão econômica. São Paulo, Annablume, 2003.

GRUPO KRISIS. Manifesto contra o trabalho. In: Cadernos do LABUR número 02, Departamento de Geografia Urbana, FFLCH/USP, 1999.

HABERMAS, Jürgen. Para a Reconstrução do Materialismo Histórico. São Paulo: Editora Brasiliense, 1993.

Teoria de lá accion communicativa. Madri: Taurus, 1999.

HARVEY, David. A Justiça Social e a Cidade. Tradução Armando Correa da Silva. São Paulo: Hucitec, 1980.

- A Produção Capitalista do Espaço. São Paulo: Annablume, 2005.

A Condição Pós-Moderna. São Paulo: Loyola, 1992. 
KURZ, Robert. O colapso da modernização. São Paulo: Paz e Terra, 1992.

LEFEBVRE, Henri. A produção do espaço. Trad. Grupo "As (im)possibilidades do urbano na metrópole contemporânea", do Núcleo de Geografia Urbana da UFMG (do original: La production de l'espace. 4e éd. Paris: Éditions Anthropos, 2000). Primeira versão: início - fev. 2006.

LESSA, Sérgio. Mundo dos Homens: trabalho e ser social. São Paulo: Instituto Lukács, 2012.

LUKÁCS, György. As Bases Ontológicas da Atividade e do Pensamento do Homem. Revista Temas, São Paulo: Ciências Humanas, n. 4, p. 1-18,1978.

História e consciência de classe: Estudos sobre a dialética marxista. São Paulo: Martins Fontes, 2003

Socialismo e democratização: escritos políticos 1956-1971. Rio de Janeiro: Editora UFRJ, 2008.

Por uma ontologia do ser social I. São Paulo: Boitempo, 2012.

. Por uma ontologia do ser social II. São Paulo: Boitempo, 2013.

. Conversando com Lukács. São Paulo: Instituto Lukács, 2014.

LUCE, Mathias Seibel. Teoria Marxista da Dependência, problemas e categorias: uma visão histórica. São Paulo: Expressão Popular, 2018.

MARINI, Ruy Mauro. Dialética da Dependência. In: TRASPADINI, R.; STÉDILE, J. P. (orgs.). Ruy Mauro Marini, vida e obra. São Paulo: Expressão Popular, 2005.

MARTINS, Élvio Rodrigues. Geografia e ontologia. GEOUSP - Espaço e tempo, São Paulo, n. 21, p. 33-51, 2007.

As dimensões do geográfico: um diálogo com Armando Corrêa da Silva. GEOUSP - Espaço e tempo, São Paulo, v. 18, n. 1, p. 40-54, 2014.

MARX, Karl. Manuscritos econômico-filosóficos. São Paulo: Boitempo, 2004.

- Grundrisse: manuscritos econômicos de 1857-58: esboços da crítica da economia. São Paulo: Boitempo, 2011.

. O Capital. Livro I. São Paulo: Boitempo, 2013.

. O Capital. Livro II. São Paulo: Boitempo, 2014.

. O Capital. Livro III. São Paulo: Boitempo, 2017. 
MENEZES, Sócrates. Geografia e trabalho; teoria e método. In: GEOPAUTA, vol. 4, núm. 4, p. 157-167, 2020.

MÉSZÁROS, István. Para além do capital: rumo à uma teoria de transição. São Paulo: Boitempo, 2002.

. A teoria da alienação em Marx. São Paulo: Boitempo, 2006.

MORAES, Antônio Carlos Robert. Em busca da ontologia do espaço. In: MOREIRA, R. Geografia: teoria e crítica. Petrópolis: Vozes, 1982.

MOREIRA, Ruy. O que é Geografia. Rio de Janeiro: Brasiliense, 1981.

. Geografia teoria e crítica: o saber posto em questão. Petrópolis/RJ: Vozes, 1982.

O movimento operário e a questão cidade-campo no Brasil: estudo sobre sociedade e espaço. Rio de Janeiro: Vozes, 1985.

Assim se passaram dez anos (A renovação da geografia no Brasil no período 1978-1988). Geographia, Niterói, ano 2, n. 3, p. 27-49, 2000.

- Trabalho e Movimentos Sociais no Brasil: um diálogo possível no âmbito da luta emancipatória? In: II Jornada sobre o Trabalho. Caderno de Textos - Centro de Estudos de Geografia do Trabalho (CEGeT), Presidente Prudente, CEGeT, 2001.

Marxismo e Geografia. A geograficidade e o diálogo das ontologias. Revista GEOgraphia. Niterói, n. 11, dez, p. 21-37, 2004.

. O pensamento geográfico brasileiro: as matrizes clássicas originárias. Vol. I. São Paulo: Contexto, 2008.

Pensar e ser em geografia. São Paulo: Contexto, 2011.

NETTO, José Paulo. Posfácio. In: COUTINHO, Carlos. Nelson. O estruturalismo e a miséria da razão. $2^{a}$ edição. SP: Expressão Popular, 2010, p. 233-286.

OFFE, Claus. Capitalismo desorganizado: transformações contemporâneas do trabalho e da política. São Paulo: Brasiliense, 1985.

OLIVEIRA, Veronica Ferraz de.; FERRAZ, Ana Emília de Quadros. A centralidade do trabalho análise geográfica. Geopauta. n 1, v. 3, Bahia - UESB, p. 103-115, 2019.

OLIVEIRA JUNIOR, Gilberto. Ontologia do espaço: critica da crítica da entificação social do ser enquanto pressuposto a uma teoria espacial interpenetrada a “ontologia do ser social”, de Gyorgy Lukacs. 2015. xvi, 481 f. Tese (Doutorado em Geografia) Universidade de Brasília, Brasília, 2015. 
OSORIO, Jaime. Dependência e superexploração. In: SANTOS, Theotonio dos; SADER, Emir (Coord.); MARTINS, Carlos Eduardo; VALENCIA, Adrián Sotelo (Org.) A América Latina e os desafios da globalização. Rio de Janeiro: Ed. Puc-rio; São Paulo: Boitempo Editorial, 2009, p. 167-188.

PEDROSA, Breno Viotto. A geografia crítica brasileira e o debate sobre ontologia do espaço: uma aproximação. Revista Geografares, Vitória, n. 11, junho, p.139168, 2012.

PRIEB, Sérgio. O trabalho à beira do abismo: uma crítica marxista à tese do fim da centralidade do trabalho. Ijuí, Editora da Unijuí, 2005.

REIS, Luis Carlos Tosta. dos. Ontologia e produção do espaço na geografia - uma abordagem do tema através do diálogo entre Milton Santos e Heidegger sobre a técnica. Geografares, Vitória, n. 13, p. 01-39, 2012.

RODRIGUES, Mavi. Michel Foucault sem espelhos: um pensador proto pósmoderno. Tese de Doutorado - Programa de Pós-Graduação da Escola de Serviço Social da Universidade Federal do Rio de Janeiro, 2006.

SANTOS, Jânio Roberto Diniz dos.; SOUZA, Suzane Tosta. Trabalho e história do pensamento geográfico nos meandros da Geografia Crítica. In: GEOPAUTA, vol. 1, núm. 1, p. 19-36, 2017.

SANTOS, Theotonio. A Teoria da Dependência: balanço e perspectivas. Santa Catarina: Insular, 2020.

SILVA, Armando Corrêa da. O espaço fora do lugar. São Paulo: HUCITEC, 1978.

SMITH, Neil. Desenvolvimento desigual: natureza, capital e a produção de espaço. Rio de Janeiro: Bertrand Brasil, 1988.

SOUZA, Suzano Tosta; SANTOS, Jânio Roberto Diniz dos.; ROCHA, Fátima Grislane Batista; LEAL, Victor Andrade Silva. A categoria trabalho na ciência geográfica, o contexto do pensamento crítico. Pegada, n. 1, v. 17, julho, UNESP - Presidente Prudente, p. 286-309, 2016.

THOMÁZ JÚNIOR, Antônio. Por uma Geografia do Trabalho. Pegada, Número Especial, v. 3, UNESP - Presidente Prudente, p. 04-26, 2002.

. (Org.). Geografia e Trabalho no Século XXI. Presidente Prudente: Centelha, 2004. Vol. 1. 
XAVIER, Glauber Lopes. O imperialismo na América Latina e a atualidade da Teoria Marxista da Dependência. In: Revista Katál., Florianópolis, v. 21, n. 2, p. 387-395, maio/ago. 2018.

YOUNG-BRUEHL, Elisabeth. Por amor ao mundo: a vida e a obra de Hannah Arendt. Rio de Janeiro: Relume-Dumará, 1997.

Submetido em: 31 de março de 2020. Aprovado em: 21 de maio de 2021. Publicado em: 23 de dezembro de 2021. 